\title{
MODELLING ANTARCTIC FAST-ICE GROWTH
}

\author{
By G.B. Crocker and P. Wadhams
}

(Scott Polar Research Institute, University of Cambridge, Cambridge CB2 IER, England)

ABSTRACT. An existing thermodynamic ice-growth model (Semtner, 1976) has been tested for its ability to predict the growth of fast ice in McMurdo Sound, Antarctica. Significant discrepancies between observed and predicted ice thicknesses were found to occur, primarily due to the presence of sub-ice platelets and the formation of a snow-ice layer. Although these ice-growth processes are not well enough understood to permit rigorous physical modelling, it is shown that fairly simple modifications to the model greatly improve the accuracy of the thickness predictions, and serve to highlight the importance of these processes in the Antarctic fast-ice environment. Surface flooding and snow-ice formation are assumed to occur immediately upon the establishment of a positive hydrostatic water level, and a surface temperature in excess of a critical value, above which interconnecting channels in the ice matrix permit the flow of water to the surface. The presence of the sub-ice platelet layer is assumed to increase columnar ice growth at a rate proportional to the volume fraction of ice in the platelet layer, a simple technique but one that permits estimates of platelet-enhanced growth without detailed knowledge of oceanographic conditions. The resulting model predictions are in close agreement with measurements of fast-ice growth and decay in McMurdo Sound; however, data suitable for testing the model over a complete range of conditions and over multi-year cycles are not available at the present time.

\section{INTRODUCTION}

Numerous thermodynamic models have been developed to predict the growth of Arctic sea ice, ranging in complexity from simple formulae based on freezing degree days (Stefan, 1889; Nakawo and Sinha, 1981) to rigorous treatments of the physics governing energy transfers between the ocean and the atmosphere (Maykut and Untersteiner, 1971; Gabison, 1987). Measurements of Arctic ice growth are also abundant and, in general, good association between observed and predicted ice thicknesses can be obtained. It may seem rational, therefore, to suppose that if the physical processes responsible for transferring energy through the ocean-ice-atmosphere system have been adequately accounted for, then these models will be equally effective at predicting the growth of Antarctic sea ice. However, most models contain parameters, such as albedo and the turbulent-energy transfer coefficients, which are site specific. More importantly, there is always the possibility that processes neglected as being either insignificant or absent in one region make important contributions to ice growth in another. In short, it is dangerous to presume $a$ priori that a thermodynamic model which has been proven to predict accurately ice growth in the Arctic will accurately predict ice growth in the Antarctic.

In this paper an existing thermodynamic ice-growth model will be tested for its ability to predict the growth of fast ice in McMurdo Sound, Antarctica, and modified to represent better the special environmental conditions found there. Although developed specifically for McMurdo Sound, and therefore encumbered with some of the problems of regionally based models mentioned above, the resulting formulation will, it is hoped, be better suited to the general problem of Antarctic fast-ice growth than those currently available.

\section{MODEL DESCRIPTION}

Since there exists very little detailed atmospheric and oceanographic information of a form suitable as input data in an Antarctic thermodynamic model, the first criterion that our formula must meet is simplicity. Since energy exchanges between the ice and the ocean strongly affect the growth of Antarctic ice (Allison, 1979), the model must also include a simple oceanic heat-flux term. An existing model which meets both of these criteria, and which has the added advantage of being well suited to the modifications required for improved representation of the physical processes influencing Antarctic ice growth, is the "zero layer" model of Semtner (1976). Like several more complex models (Maykut and Untersteiner, 1971; Gabison, 1987), Semtner's formula relies on a calculated equilibrium surface temperature, from which all the necessary surface fluxes can be determined. This is accomplished by assuming that the flux of energy to the surface through the snow/ice slab $\left(F_{0}\right)$ is equal to the sum of all the fluxes transferring energy from the surface to the atmosphere $\left(F_{\mathbf{a}}\right)$, that is

$$
F_{0}+F_{\mathrm{a}}=0
$$

where an upward flux is considered positive. For bare ice, $F_{0}$ is calculated using

$$
F_{0}=\frac{k_{\mathrm{i}}\left(T_{\mathrm{b}}-T_{0}\right)}{h_{\mathrm{i}}}
$$

and for snow-covered ice

$$
F_{0}=\frac{k_{\mathrm{s}}\left(T_{\mathrm{b}}-T_{0}\right)}{h_{\mathrm{s}}+\left(h_{\mathrm{i}} k_{\mathrm{s}} / k_{\mathrm{i}}\right)}
$$

where $k$ is thermal conductivity, $h$ is thickness, the subscripts $s$ and $i$ refer to the snow and ice, respectively, $T_{b}$ is the temperature at the ice/water interface, and $T_{0}$ is the surface temperature. The flux to the atmosphere is

$$
F_{\mathrm{a}}=F_{\mathrm{S}}+F_{\mathrm{l}}+F_{\mathrm{Ld}}+(1-\alpha) F_{\mathrm{r}}+\varepsilon \sigma T_{0}^{4}
$$

where the subscripts $s, l, L d$, and $r$ refer to fluxes of sensible, latent, incoming long-wave radiation, and incoming short-wave radiation, respectively, $\alpha$ is the surface albedo, $\varepsilon$ is the surface emissivity, and $\sigma$ is the Stefan-Boltzmann constant. In this simplified model, it is assumed that the fraction of incoming solar radiation which penetrates the snow or ice surface $\left(I_{0}\right)$ is zero. This has the effect of increasing the predicted surface temperature, and with the imposed linear temperature profile through the ice, results in a slight underprediction of ice growth. Semtner (1976) corrected this by increasing $k_{\mathrm{i}}$ and $k_{\mathrm{s}}$ by a factor of 1.065 , a procedure which has been adopted here.

The first four terms on the right side of Equation (4) must be supplied as input data, allowing $T_{0}$ to be 
determined by a Newton-Raphson or similar iterative process. By substituting $T_{0}$ into Equations (2) (or (3)) and (4), the change in thickness at the base of the ice sheet $\left(\Delta h_{\mathrm{b}}\right)$ can then be calculated using

$$
\Delta h_{\mathrm{b}}=\Delta t\left(F_{\mathrm{0}}-F_{\mathrm{b}}\right) / q_{\mathrm{b}}
$$

where $\Delta t$ is the time increment, $F_{\mathrm{b}}$ is the oceanic heat-flux term (also explicitly defined), and $q_{\mathrm{b}}$ is the volumetric heat of fusion at the bottom of the ice cover.

If the surface temperature is found to be above the freezing point, then surface melting is determined by computing $F_{\mathrm{a}}$ and $F_{0}$ for $T_{\mathrm{s}}=0$, and setting

$$
\Delta h_{\mathrm{s}}=\Delta t\left(F_{\mathrm{a}}-F_{0}\right) / q_{\mathrm{s}}
$$

for snow-covered ice, and

$$
\Delta h_{\mathrm{i}}=\Delta t\left(F_{\mathrm{a}}-F_{0}\right) / q_{\mathrm{i}}
$$

for bare ice, where $q_{\mathrm{S}}$ and $q_{\mathrm{i}}$ are the volumetric heats of fusion for snow and ice, respectively.

However, in this form the model is difficult to apply to Antarctic fast-ice growth. Observations of ice growth in McMurdo Sound during the austral winter of 1986 (Crocker, unpublished) showed two additional processes to be making significant contributions to ice growth: the formation of snow-ice, and the formation of a sub-ice platelet layer.

\section{Snow-ice}

In near-shore areas, where snow blown off the Antarctic continent accumulates in large quantities, the resulting overburden pressure can lead to flooding of the ice surface and the formation of snow-ice. It has been observed in some coastal zones that snow-ice is the main constituent of the fast-ice sheet (Kozlovskiy, 1981). Snowice has also been found in abundance in the winter pack-ice cover, where high oceanic heat fluxes restrict the annual ice growth to $0.6-0.8 \mathrm{~m}$, and flooding is possible on a large scale even though the snow accumulations are less (Wadhams and others, 1987). If estimates of the snow and ice densities are available, then the equilibrium hydrostatic water level $\left(H_{\mathrm{w}}\right)$ can easily be calculated using

$$
H_{\mathrm{w}}=\frac{\rho_{\mathrm{i}}}{\rho_{\mathrm{w}}} h_{\mathrm{s}}-\frac{\rho_{\mathrm{i}}}{\rho_{\mathrm{s}}} h_{\mathrm{i}}\left[1-\frac{\rho_{\mathrm{i}}}{\rho_{\mathrm{w}}}\right)
$$

where $\rho$ is density, $h$ is thickness, and the subscripts $i, s$, and $w$ refer to ice, snow, and water, respectively (Röthlisberger, 1963). Determining exactly when, or if, flooding will occur is considerably more difficult. A reasonable assumption might be that surface flooding will take place as soon as $H_{\mathrm{w}}$ becomes positive. If, as observations indicate, flooding occurs in discrete events but eventually reaches equilibrium levels, then although the timing would be incorrect, the resulting error in the growth calculations would be small. However, the McMurdo Sound observations throw some doubt on the validity of this assumption. Throughout the winter, drill holes revealed consistently positive hydrostatic water levels, but there was a conspicuous absence of large-scale flooding. Because sea ice normally does not crack under thermally induced stress, in order for positive $H_{\mathrm{w}}$ values to be relieved flow must take place through interconnecting channels in the ice. Pounder (1965) suggested that the transition between interconnected and discontinuous brine-drainage channels occurs at a temperature of roughly $-15^{\circ} \mathrm{C}$. This figure will be highly dependent upon the salinity and crystal structure of the ice, and measurements of ice-surface temperatures in McMurdo Sound during several flooding events showed that a value of $-8^{\circ} \mathrm{C}$ is more appropriate in this specific case. We therefore have two criteria which must be satisfied before flooding can occur: positive hydrostatic water levels, and surface temperatures greater than or equal to $-8^{\circ} \mathrm{C}$. It is recognized that imposing a constant minimum temperature for flooding is a crude approximation, but very little is known about the relationships between the temperature, salinity, and crystal structure of sea ice and its permeability and, until such information becomes available, the threshold temperature criterion must suffice.

It is assumed that the transport of liquid to the surface has no effect on the thermodynamics of the ice sheet, apart from the obvious effects of changes in $h_{\mathrm{s}}$ and the thickness of the snow-ice layer $\left(h_{\mathrm{si}}\right)$. Spot measurements made on the ice immediately in front of Scott Base in March 1986 showed the flooding liquid to be high-salinity brine $(\approx 125 \mathrm{ppt})$, at roughly the same temperature as the snow into which it was flowing (indicating that flooding takes place through the brine-drainage network rather than through stress fractures, and that the liquid in the brine pockets is pushed to the surface ahead of the ocean water below). The snow/liquid mixture produced is therefore highly saline (about $70 \mathrm{ppt}$ ), but the temperature profile through the ice remains virtually unchanged, and the amount of advected heat energy is quite small. We have also assumed that the amount of latent heat released as the flooded layer solidifies is negligible. This is of course not strictly true, but McMurdo Sound observations suggest that the amount of latent heat released from the flooded layer is small. Since the temperature and salinity of the flooding liquid do not change when mixed with the snow, the mixture will be in a state of chemical equilibrium for that temperature. The observed salinity of $70 \mathrm{ppt}$, and temperature of $-8^{\circ} \mathrm{C}$, indicates that the brine volume in the mixture was about 465 ppt (Frankenstein and Garner, 1967), and therefore the volume of ice was roughly $500 \mathrm{ppt}$, slightly greater than the $350 \mathrm{ppt}$ occupied by the ice grains in the original snow layer. Since the temperature did not change, most of this increase must be due to compaction of the snow on flooding. In fact, in the absence of any significant decrease in temperature, most of the solidification of the snow-ice layer must be the result of compaction of the snow in the presence of the liquid." Although reductions in the temperature of the flooded layer will result in some freezing of the flooded liquid, the deep snow cover which remains over the "snow-ice" layer acts to moderate atmospheric temperature fluctuations, and in this case the observed brine-volume decrease resulted primarily from snow compaction and drainage of the interstitial fluid after the initial flooding event (the salinity of the snow-ice layer was $70 \mathrm{ppt}$ on 1 March, $44 \mathrm{ppt}$ on 30 March, and $15 \mathrm{ppt}$ several months later when the sample shown in Figure 1 was taken). It is not known to what extent freezing of the flooding liquid contributes to snow-ice formation on a regional scale (this subject should be investigated further); however, we feel that the errors introduced into this simple type of ice-growth model by neglecting the latent heat released from the snow-ice layer will be small.

Equation (8) is based on the assumption that the flooded layer becomes completely saturated. This is clearly not true, as close examination of the ice revealed numerous small air pockets trapped in the ice matrix (see Fig. 1). Qualitative observations of the snow-ice in McMurdo Sound show that its air-bubble content is similar to that of snowice formed on lakes. Adams (1981) has measured the density of lake snow-ice and we adopt his value for $\rho_{s i}$ of $820 \mathrm{~kg} \mathrm{~m}^{-3}$ (corresponding to an air-bubble content of $10 \%$ ), and adjust the calculated hydrostatic water levels by increasing $H_{\mathrm{W}}$ uniformly by $10 \%$. Also, because both brine and air are poorer conductors than pure ice, the low density and high salinity of the snow-ice layer will combine to reduce its thermal conductivity. To estimate the magnitude of this reduction, we use Schwerdtfeger's (1963) model for the thermal conductivity of bubbly, saline ice as representative of the thermal conductivity of snow-ice $\left(k_{\mathrm{si}}\right)$. Then $k_{\text {si }}$ can be calculated using

$$
k_{\mathrm{si}}=k_{\mathrm{bi}}-\left(k_{\mathrm{bi}}-k_{\mathrm{b}}\right) \frac{5 \rho_{\mathrm{si}}}{\mu \rho_{\mathrm{w}} T}
$$

where $S$ is the ice salinity in parts per thousand, $T$ is the ice temperature in degrees Celsius, $\mu$ is a constant $\left(-0.0182^{\circ} \mathrm{C}^{-1}\right), k_{\mathrm{b}}$ is the thermal conductivity of brine

$$
k_{\mathrm{b}}=0.4184\left(1.25+0.03 T+0.00014 T^{2}\right)
$$




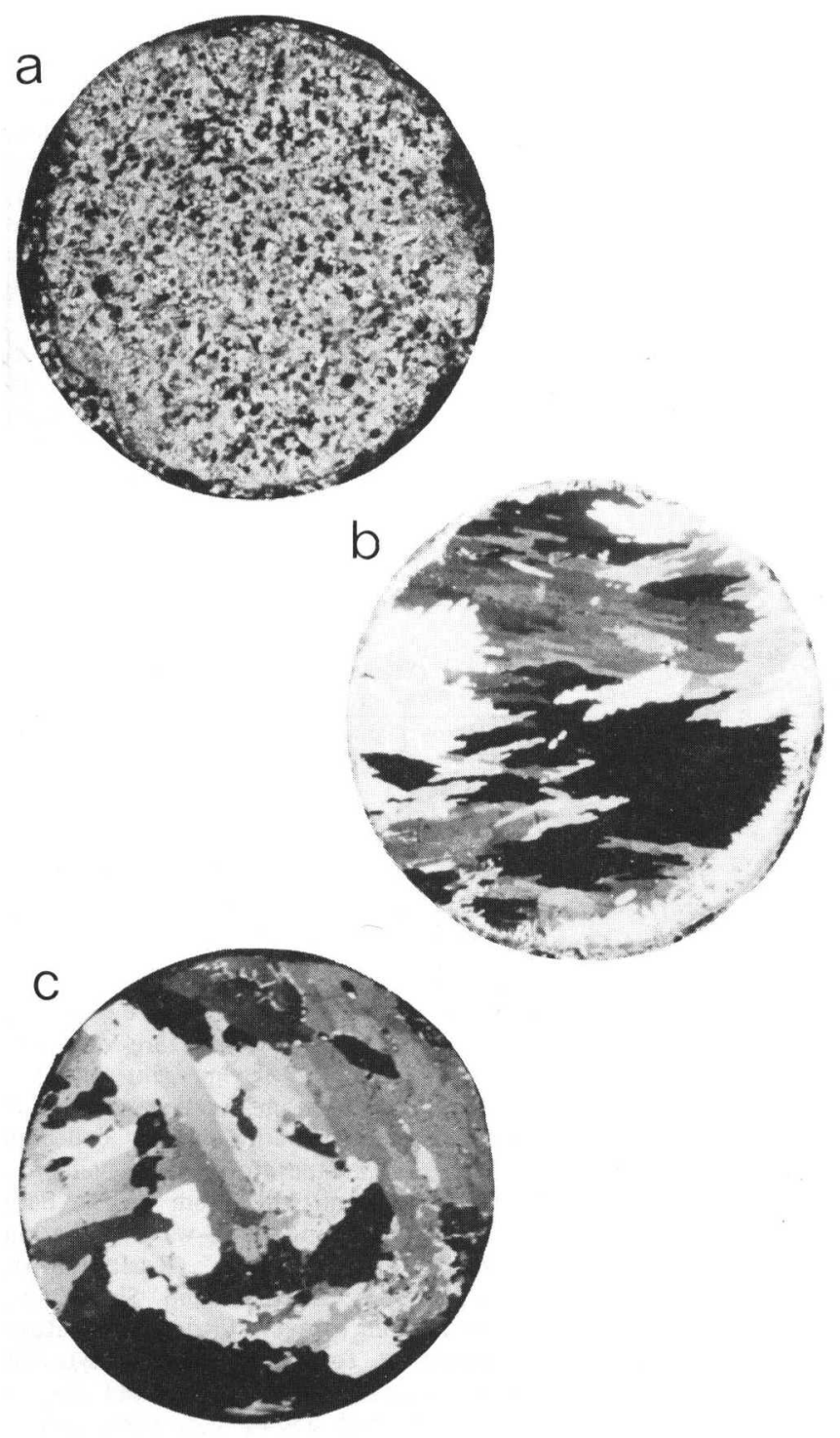

Fig. 1. Vertical crossed-polaroid photographs of (a) snow-ice, (b) columnar ice, and (c) ice formed by columnar growth into a sub-ice platelet layer. All three thin sections are from cores taken in McMurdo Sound during the winter of 1986; (a) and (c) from roughly $1.5 \mathrm{~km}$ offshore from Pram Point, and (b) about $100 \mathrm{~m}$ from shore in North Bay. Each section is $76 \mathrm{~mm}$ in diameter.

$k_{\mathrm{bi}}$ is the thermal conductivity of bubbly ice

$$
k_{\mathrm{bi}}=\frac{2 k_{\mathrm{o}}+k_{\mathrm{a}}-2 V_{\mathrm{a}}\left(k_{0}-k_{\mathrm{a}}\right)}{2 k_{\mathrm{o}}+k_{\mathrm{a}}-V_{\mathrm{a}}\left(k_{\mathrm{o}}-k_{\mathrm{a}}\right)},
$$

$k_{\mathrm{a}}$ is the thermal conductivity of air, $V_{\mathrm{a}}$ is the volume fraction of air, and $k_{0}$ is the thermal conductivity of pure ice (Schwerdtfeger, 1963). At $-10^{\circ} \mathrm{C}$ and a salinity of $20 \mathrm{ppt}$, Equation (9) gives $k_{\mathrm{si}}=1.66 \mathrm{~W} \mathrm{~m}^{-1} \mathrm{~K}^{-1}$ which is about $10 \%$ less than a value of $k_{i}$ for "normal" sea ice calculated using Untersteiner's (1961) formula

$$
k_{\mathrm{i}}=k_{0}+\frac{B S}{T}
$$

in which $\beta$ is a constant $\left(0.117 \mathrm{~W} \mathrm{~m}^{2} \mathrm{~kg}^{-1}\right)$, and $S$ and $T$ are again in parts per thousand and degrees Celsius. For simplicity, we therefore set $k_{\mathrm{si}}$ to $0.9 \times k_{\mathrm{i}}$ throughout the calculations. An additional alteration must then be made to accommodate the three-layer (ice, snow-ice, and snow) system of series-connected conductors. This is accomplished by replacing Equations (2) and (3) with

$$
F_{0}=\frac{\left(T_{\mathrm{b}}-T_{0}\right)}{\frac{h_{\mathrm{i}}}{k_{\mathrm{i}}}+\frac{h_{\mathrm{si}}}{k_{\mathrm{si}}}+\frac{h_{\mathrm{s}}}{k_{\mathrm{s}}}}
$$

(see Leppäranta, 1983).

\section{Sub-ice platelets}

A second modification which must be made to the model is to incorporate the contribution to growth of the sub-ice platelets; discoid, single crystals of ice formed when supercooled water comes in contact with the base of the ice sheet. They normally take the shape of plates roughly $5 \mathrm{~mm}$ thick and ranging in diameter from less than $10 \mathrm{~mm}$ to over $150 \mathrm{~mm}$. Supercooled water and sub-ice platelets have been observed several times near ice-shelf margins in the Antarctic (Kozlovskiy and Cherepanov, 1976; Foldvik and others, 1985), and the general mechanism of formation has been described by Robin (1979). Although tidally modified, the currents in McMurdo Sound are principally from under the McMurdo Ice Shelf (Lewis and Perkin, 1985) and therefore fit Robin's explanation. The water flowing into McMurdo Sound originates in the Ross Sea and flows under the Ross Ice Shelf at roughly its mid-point (Jacobs and others, 1979; Pillsbury and Jacobs, 1985). As the water moves southward, it is forced to greater depths by the overlying ice shelf, and may exceed the pressure-reduced melting point at the ice-shelf bottom even if its initial temperature was equal to the surface freezing point. The heat consumed in melting basal ice is drawn from the water, and reduces its temperature. If this heat loss is sufficient to lower the water temperature to below the surface freezing point, then on the return journey northward into McMurdo Sound it will become slightly supercooled as it rises to the surface and the pressure is released. The supercooling is relieved when the water comes in contact with the bottom of the ice sheet and nucleation results in the formation of a sub-ice platelet layer. The platelets will form under both sea and shelf ice, wherever a sufficient pressure reduction has occurred to produce super-cooling, but the greatest quantities will be produced where the pressure is lowest, that is at the base of the sea-ice sheet. It is also possible for sub-ice platelets to form at depth (Dieckmann and others, 1986), in which case they would simply float upward and accumulate on the underside of the ice, but there was no evidence to suggest that nucleation was occurring in the water column in McMurdo Sound during the winter of 1986.

It is interesting to see that the thickest platelet layers measured during two transects across McMurdo Sound on 4 August and 17 October correspond to the areas of maximum surface supercooling recorded by Lewis and Perkin (1985). The timing of the platelets' first appearance and growth is also significant. The thickness of the platelet layer was observed to be increasing from early July, when it first appeared, until about mid-September, after which it remained fairly constant. Wright and Priestley (1922) found that platelets grew on their manilla lines between 5 August and 12 October 1911, and between 28 August and 28 September 1912. The later dates of first appearance of the crystals may be the result of the greater distance of their measurement site (which was roughly half-way between Cape Evans and Inaccessible Island (Deacon, 1975)) from the ice-shelf edge; nevertheless, their observations suggest that the phenomenon occurs at about the same time each year. This can be readily explained by referring to Robin's (1979) theory. The water rising out from under the McMurdo Ice Shelf will be supercooled only if it were initially near its freezing point as it flowed under the Ross Ice Shelf. For supercooling (as opposed to merely cooling) to occur in the return flow, the water must lose enough heat through basal melting to have its temperature reduced to below the surface freezing point. The absence of platelet growth until mid-winter, and a reasonable estimate of the residence time of water under the ice shelf of 2-3 months, suggests that the water in the Ross Sea is not sufficiently cooled until early winter (roughly the month of May). There is no evidence to indicate that, as Wright and Priestley (1922) hypothesized, changes in the currents themselves are 
responsible for the timing of the phenomenon, although it cannot be ruled out as a possible contributing factor.

Considering the thermodynamics of platelet growth on a regional scale, if we assume that a platelet layer $1.0 \mathrm{~m}$ thick, consisting of $50 \%$ ice and $50 \%$ sea-water, forms under the ice cover over a $60 \mathrm{~d}$ period, and that the layer extends horizontally away from the ice-shelf edge a distance of $20 \mathrm{~km}$ (figures based on measurements during the 1986 season), then $9 \times 10^{6} \mathrm{~kg}$ of ice will be formed per metre width of ice shelf. Assuming that the "active" water column extends to a depth of $100 \mathrm{~m}$ (Lewis and Perkin, 1985) and the average rate of flow out from under the ice shelf is $0.10 \mathrm{~m} \mathrm{~s}^{-1}$ (Gilmour and others, 1962; Tressler and Ommundsen, 1962; Heath, 1977), then $5 \times 10^{7} \mathrm{~m}^{3}$ of water per unit width will be acting to form the platelet layer over the $60 \mathrm{~d}$ period. Given that $L_{\mathrm{i}}=2.5 \times 10^{5} \mathrm{~J} \mathrm{~kg}^{-1}$ and $c_{\mathrm{p}}=4.2 \times 10^{6} \mathrm{~J} \mathrm{~m}^{-3}{ }^{\circ} \mathrm{C}^{-1}$, then the $2.25 \times 10^{12} \mathrm{~J} \mathrm{~m}^{-1}$ released on freezing corresponds to a mean supercooling in the active layer of $0.011^{\circ} \mathrm{C}$, which is of the same order as, though slightly lower than, the values of surface supercooling of $0.03^{\circ} \mathrm{C}$ observed by Lewis and Perkin (1985). Using the same assumptions, the ice-growth rate would be $9.6 \times 10^{-5} \mathrm{~kg} \mathrm{~s}^{-1} \mathrm{~m}^{-2}$, giving a mean oceanic heat flux of $-24 \mathrm{~W} \mathrm{~m}^{-2}$. However, because only a part of the ice formed in this manner actually becomes incorporated into the ice sheet (see Fig. 1), the remainder forming an unconsolidated mass of platelets beneath the ice which melts when the water column warms in spring, we cannot simply set $F_{\mathrm{b}}$ to $-24 \mathrm{~W} \mathrm{~m}^{-2}$. The influence of the platelets on the growth of the solid ice sheet is therefore as dependent on the conductive flux of heat through the slab, and the columnar growth which results, as it is on the growth of the platelets themselves. A more realistic solution to the platelet problem might be simply to increase the columnar ice-growth rate during the period that the platelets are present by an amount proportional to the volume of the platelet layer occupied by ice. For example, if the platelet layer is $50 \%$ ice, then $\Delta h_{\mathrm{B}}$ would be multipled by two each day the platelet layer is present. This is of course a great over-simplification because it ignores the effects of energy and salt transfers due to the formation of the platelets, and the physical changes to the ice bottom due to their presence. It has the advantages of being both simple and requiring no detailed information about the rate of platelet growth.

\section{Turbulent fluxes}

A third, but relatively minor, change from the Semtner model is the calculation, rather than explicit definition, of the turbulent fluxes $F_{\mathrm{s}}$ and $F_{\ell}$. This is achieved using the aerodynamic formulae

$$
F_{\mathrm{s}}=\rho_{\mathrm{a}} c_{\mathrm{pa}} C_{\mathrm{s}} u\left(T_{\mathrm{a}}-T_{0}\right)
$$

and

$$
F_{\ell}=0.622 \rho_{\mathrm{a}} C_{\mathrm{l}} u\left(f e_{\mathrm{sa}}-e_{\mathrm{s} 0}\right) / p_{0} .
$$

Here $\rho_{\mathrm{a}}$ is the density of air, $c_{\mathrm{pa}}$ is the specific heat of air, $u$ is the mean wind speed, $C_{\mathrm{s}}$ and $C_{l}$ are the sensible and latent energy-transfer coefficients $\left(1.75 \times 10^{-3}\right.$. (Overland, 1985)), $f$ is the relative humidity, $p_{0}$ is the surface pressure, and $e_{\mathrm{sa}}$ and $e_{\mathrm{so}}$ are the saturation vapour pressures of the air and at the surface, respectively. Maykut's (1978) fourth-order polynomial approximation is used to estimate $e_{\mathrm{sa}}$ and $e_{\mathrm{so}}$ from the air and surface temperatures, and $f$ and $p_{0}$ are assumed to be constant, with typical Antarctic values of 0.6 and $1013 \mathrm{mbar}$, respectively.

\section{RESULTS AND DISCUSSION}

\section{Predicted and observed ice growth}

Figure 2 shows measured ice-core lengths from McMurdo Sound along with columnar and snow-ice thicknesses predicted by the original and modified versions of the Semtner model, after setting the initial conditions to observed values. Although many more ice-thickness measurements were made, difficulties in accurately determining the base of the ice sheet in the presence of a

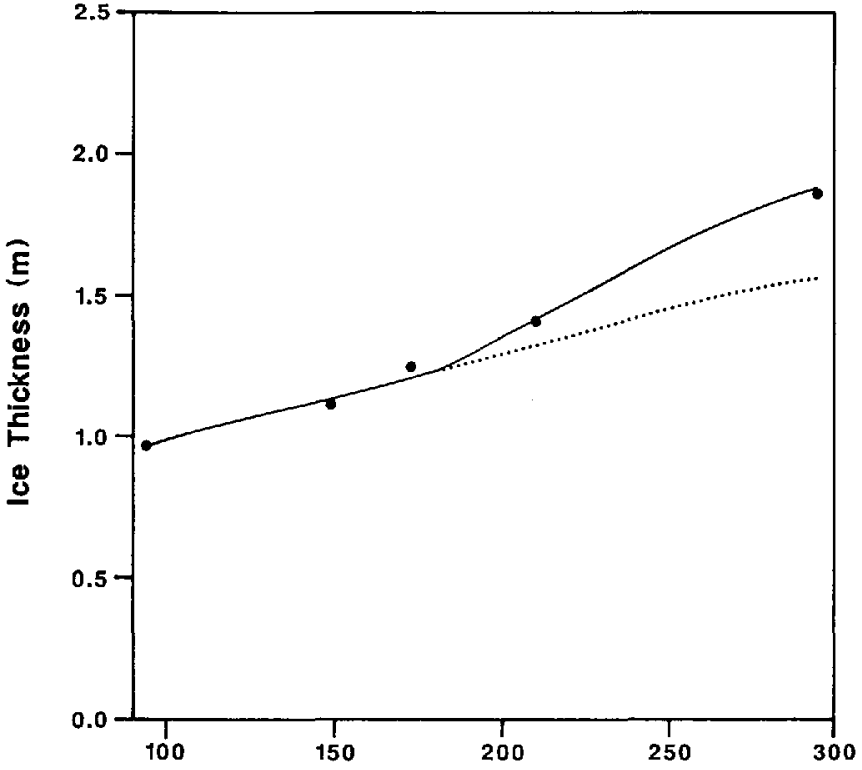

Julian Day

Fig. 2. Ice thicknesses predicted by the original (dotted line) and modified (solid line) version of the Seminer model, along with five measured ice-core lengths (large dots).

sub-ice platelet layer caused an unacceptable degree of uncertainty in the values of $h_{\mathrm{i}}$, and only the core data can be considered sufficiently reliable for the present purpose. Input data for $T_{\mathrm{a}}, u, F_{\mathrm{r}}$, and $F_{\mathrm{Ld}}$ have been modelled using Fourier transforms of mean monthly data collected from a variety of sources. Air temperature, wind velocity, and incoming short-wave radiation are from Scott Base meteorological records, while incoming long-wave radiation is a synthesis of Antarctic measurements (Rusin, 1961; Thompson and MacDonald, 1962, Zaitseva and Shlyakhov, 1984) and values estimated from observed air temperature and cloud data, using empirical formulae (Oke, 1978). On the basis of observations, $\alpha, S$, and $\rho_{s}$ have been set at constant values of $0.75,6 \mathrm{ppt}$, and $350 \mathrm{~kg} \mathrm{~m}^{-3}$, respectively. Changes in snow depth are represented by a linear increase of $0.35 \mathrm{~m}$ during the month of May, and held constant for the remainder of the year, while the thermal conductivity of the snow was calculated using the empirical formula of Abel's (1893). The timing and quantity of sub-ice platelet growth were also based on measured values, and the density of the ice was fixed at $910 \mathrm{~kg} \mathrm{~m}^{-3}$ (Anderson, 1960).

The agreement between the observed ice thicknesses and those predicted by the modified version of the model (solid line) is quite good, while the original model significantly under-predicts ice growth. Similar underpredictions resulted when the models of Maykut (1978) and Nakawo and Sinha (1981) were run with the same input data (Crocker, unpublished). As there was no flooding or snow-ice formation during the observation period (and none was predicted by the model), the improved predictions of the modified model are solely a result of including the influence of the sub-ice platelet layer on ice growth. Unfortunately, there are no data currently available which can be used to test the flooding and snow-ice growth parts of the model. Some isolated flooding events were observed at the end of the measurement period in mid-October, when the ice-surface temperature approached the prescribed threshold, but our treatment of the snow-ice growth process remains for the time being unproven. Bearing this in mind, it is nevertheless interesting to look at the patterns of ice growth and decay predicted by the model over the course of several seasonal cycles.

Multi-year projections

In order to extend the thickness predictions through the summer ablation period, we must first define a term accounting for basal melting. From measured summer oceanic heat fluxes (Mitchell and Bye, 1985), summer melting is simulated by setting $F_{0}$ to a constant value of $+70 \mathrm{~W} \mathrm{~m}^{-2}$ through the months of November, December, 
January, and February. This heat energy is used first to melt the sub-ice platelet layer, and begins to reduce the thickness of the ice sheet only when all the platelets have been removed. An indication that this rather crude technique is at least generally representative of actual conditions can be found in the observation that both model predictions and measurements (Paige and Lee, 1967) of the timing and magnitude of ice-sheet ablation coincide quite closely.

Figure 3 shows forecast growth and decay cycles over a 5 year period. Snow-ice does not form in appreciable quantities until the second summer, when a deep snow pack, the reduced winter growth accompanying it, and

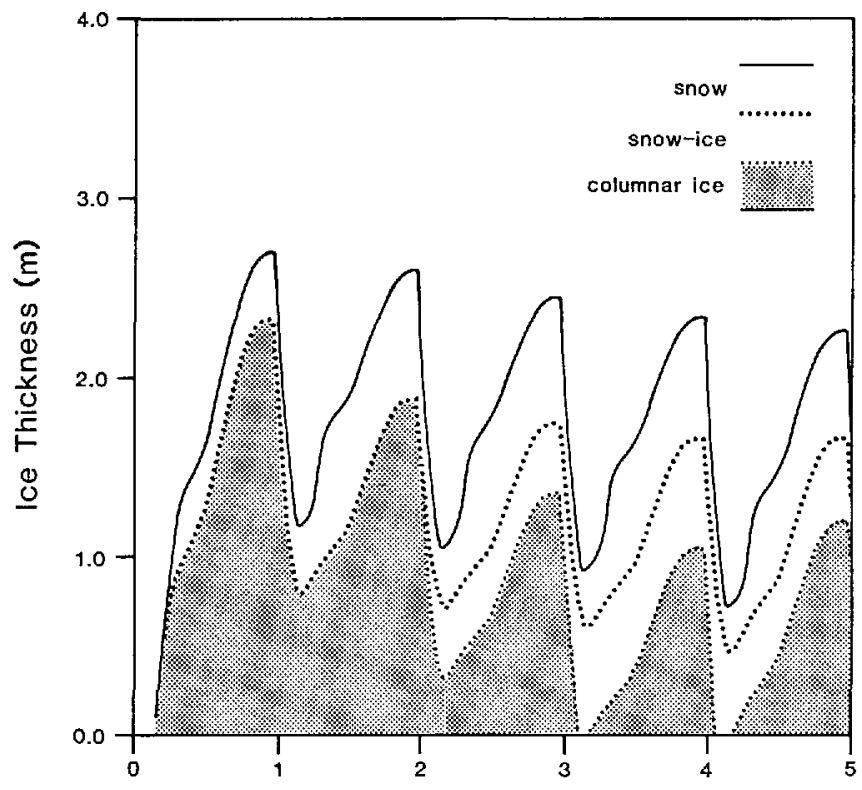

Time (years)

Fig. 3. Predicted growth and decay cycles for snow, snow-ice, and columnar ice in McMurdo Sound over a 5 year period. It is assumed that freeze-up occurs on I March in year 1.

basal melt during the summer, combine to produce the necessary conditions of $H_{\mathrm{w}}$ and $T_{0}$. There is a consistent reduction in the total ice thickness with time after the first winter, as the increased snow depth, and to a lesser extent the increased snow-ice depth, reduce the flow of heat through the slab. After 5 years, equilibrium conditions are reached, with snow-ice constituting just over $25 \%$ of the total thickness at the end of winter peak, and $100 \%$ of the total during the summer minimum. The predicted lack of surface melting, a product of the relatively strong winds and dry air prevalent during the summer (Andreas and Ackley, 1982), is consistent with observations, and has been found to be characteristic of Antarctic sea ice. The general pattern and magnitude of the thickness oscillations are also in agreement with observations from the multi-year fast ice in the southern end of McMurdo Sound, although it is difficult to assess the snow-ice predictions without corresponding snow-depth data. As a result, any assessment of the influence of different snow-accumulation regimes on the growth characteristics of the ice can only be considered tentative, but several features of the analysis are noteworthy.

Since snow deposition is normally greatest near the coast, and decreases markedly with distance from shore, the range of snow conditions likely to be found in McMurdo Sound can be modelled by varying the snow accumulation from $0.35 \mathrm{~m} \mathrm{a}^{-1}$ to extremes of 1.00 and $0.05 \mathrm{~m} \mathrm{a}^{-1}$. With a deep snow-pack, true equilibrium conditions are not realized; rather a repeating 3 year cycle is established in which $h_{i}$ progressively increases and $h_{s i}$ is progressively reduced, but on average snow-ice thicknesses are much greater than with $0.35 \mathrm{~m}$ of snow per year. Annual accumulations of $0.05 \mathrm{~m}$, on the other hand, result in large initial columnar ice thicknesses $(* 3.0 \mathrm{~m})$ and a complete absence of snow-ice until the eighth winter, with an equilibrium not being established for over 20 years. When equilibrium conditions are reached, however, the total ice thickness at the end of winter maximum is only $1.85 \mathrm{~m}$, $0.40 \mathrm{~m}$ of which is snow-ice.

Also, in the absence of surface melting, the equilibrium thickness is controlled by the summer oceanic heat flux. For example, reducing $F_{b}$ by $75 \%$ produces a predicted equilibrium thickness (with $0.35 \mathrm{~m} \mathrm{a}^{-1}$ of snow) of over $10 \mathrm{~m}$, providing a possible explanation for reports of extremely thick, old, sea ice near the edge of the McMurdo Ice Shelf (Hoffman and Stehle, 1963). Unfortunately, crystallographic observations from this or other multi-year ice sheets are not available, and the predicted proportions of columnar and snow-ice cannot be verified.

\section{SUMMARY}

The growth of fast ice in McMurdo Sound is strongly influenced by the presence of a sub-ice platelet layer, and by surface flooding under heavy snow loads. The importance of these phenomena, and their effects on ice growth and thermodynamics has been discussed, and it is shown that the thermodynamic ice-growth model of Semtner (1976) can be used to predict ice-thickness changes when modified slightly to account for the presence of the platelets and the formation of snow-ice. The modifications applied here are quite crude, however the phenomena themselves are poorly understood, and at the present time more sophisticated attempts to physically model them are not possible. Agreement between observed and predicted ice thicknesses is good, both before and after a sub-ice platelet layer has formed, but there are still insufficient data to test fully the snow-ice growth predictions.

The model can also be used to predict ice growth and decay over several seasonal cycles, and yields some interesting patterns which should be investigated in future field studies. The model modifications have been aimed specifically at describing growth processes in McMurdo Sound. However, it is hoped that an improved representation of Antarctic fast-ice growth in general has been achieved and, perhaps more importantly, that we have brought to light some of the special processes associated with the growth of Antarctic fast-ice sheets, processes which must be accounted for if more physically rigorous Antarctic ice-growth models are to be developed.

\section{ACKNOWLEDGEMENTS}

This project was supported by the U.K. Natural Environment Research Council under grant GR/5713A. G.B.C. was supported in Cambridge by the Natural Sciences and Engineering Research Council of Canada, and in the Antarctic by the Antarctic Division of the New Zealand Department of Scientific and Industrial Research. The assistance of the 1986 winter-over crew at Scott Base is gratefully acknowledged.

\section{REFERENCES}

Abel's, G. 1893. [Diurnal course of snow temperature and determination of the relationship between its thermal conductivity and density.] Zap. Imperatorskoy Akad. Nauk, 72, Suppl. 12. [In Russian.]

Adams, W.P. 1981. Snow and ice on lakes. In Gray, D.M and D.H. Male, eds. Handbook of snow: principles, processes, management, and use. Toronto, Pergamon Press, 437-474.

Allison, I. 1979. Antarctic sea ice growth and ocean heat flux. International Association of Hydrological Sciences Publication 131 (Symposium at Canberra 1979 - Sea Level, Ice and Climatic Change), 161-170.

Anderson, D.L. 1960. The physical constants of sea ice. Research, 13(8), 310-318.

Andreas, E.L. and S.F. Ackley. 1982. On the differences in ablation seasons of Arctic and Antarctic sea ice. $J$. Atmos. Sci., 39(2), 440-447. 
Crocker, G.B. Unpublished. Physical processes in Antarctic landfast sea ice. (Ph.D. thesis, University of Cambridge, 1988.)

Deacon, G.E.R. 1975. The oceanographical observations of Scott's last expedition. Polar Rec., 17(109), 391-396.

Dieckmann, G., G. Rohardt, H, Hellmer, and J. Kipfstuhl. 1986. The occurrence of ice platelets at $250 \mathrm{~m}$ depth near the Filchner Ice Shelf and its significance for sea ice biology. Deep Sea Res., Pt. A, 33(2), 141-148.

Foldvik, A., T. Gammelsrød, and T. Tørresen. 1985. Circulation and water masses on the southern Weddell Sea shelf. In Jacobs, S.S., ed. Oceanology of the Antarctic continental shelf. Washington, DC, American Geophysical Union, 5-20. (Antarct. Res. Ser., 43.)

Frankenstein, G. and R. Garner. 1967. Equations for determining the brine volume of sea ice from $-0.5^{\circ}$ to $-22.9^{\circ} \mathrm{C}$. J. Glaciol., 6(48), 943-944.

Gabison, R. 1987. A thermodynamic model of the formation, growth, and decay of first-year sea ice. $J$. Glaciol., 33(113), 105-119.

Gilmour, A.E., W.J.P. MacDonald, and F.G. van der

Hoeven. 1962. Winter measurements of sea currents in McMurdo Sound. N.Z. J. Geol. Geophys., 5, 778-789.

Heath, R.A. 1977. Circulation across the ice shelf edge in McMurdo Sound, Antarctica. In Dunbar, M.J., ed. Polar oceans. Proceedings of the Polar Oceans Conference held at McGill University, Montréal, May 1974. Calgary, Arctic Institute of North America, 129-150.

Hoffman, C.R. and N.S. Stehle. 1963. Sea ice studies on McMurdo Sound during Deep Freeze 62. Port Hueneme, CA, U.S. Naval Engineering Laboratory. (Tech. Note N-494.)

Jacobs, S.S., A.L. Gordon, and J.L. Ardai, jr. 1979. Circulation and melting beneath the Ross Ice Shelf. Science, 203(4379), 439-443.

Kozlovskiy, A.M. 1981. Snow measurements on Antarctic fast ice. Polar Geogr. Geol., 5(3), 171-174.

Kozlovskiy, A.M. and N.V. Cherepanov. 1976. The effect of coastal morphological features on the formation of underwater ice in Antarctic seas. Hanover, NH, U.S. Army Cold Regions and Engineering Laboratory. (Draft Translation 654.)

Leppäranta, M. 1983. A growth model for black ice, snow ice and snow thickness in subarctic basins. Nord. Hydrol., 14(2), 59-70.

Lewis, E.L. and R.G. Perkin. 1985. The winter oceanography of McMurdo Sound, Antarctica. In Jacobs, S.S., ed. Oceanology of the Antarctic continental shelf. Washington, DC, American Geophysical Union, 145-165. (Antarct. Res. Ser., 43.)

Maykut, G.A. 1978. Energy exchange over young sea ice in the central Arctic. J. Geophys. Res., 83(C7), 3646-3658

Mitchell, W.M. and J.A.T. Bye. 1985. Observations in the boundary layer under the sea ice in McMurdo Sound. In Jacobs, S.S., ed. Oceanology of the Antarctic continental shelf. Washington, DC, American Geophysical Union, 167-176. (Antarct. Res. Ser., 43.)

Nakawo, M. and N.K. Sinha. 1981. Growth rate and salinity profile of first-year sea ice in the high Arctic. J. Glaciol., 27(96), 315-330.

Oke, T.R. 1978. Boundary layer climates. London, Methuen.

Overland, J.E. 1985. Atmospheric boundary layer structure and drag coefficients over sea ice. J. Geophys. Res., 90(C5), 9029-9049.

Paige, R.A. and C.W. Lee. 1967. Preliminary studies on sea ice in McMurdo Sound, Antarctica, during "Deep Freeze 65". J. Glaciol., 6(46), 515-528.

Pillsbury, R.D. and S.S. Jacobs. 1985. Preliminary observations from long-term current meter moorings near the Ross Ice Shelf, Antarctica. In Jacobs, S.S., ed. Oceanology of the Antarctic continental shelf. Washington, DC, American Geophysical Union, 87-107. (Antarct. Res. Ser., 43.)

Pounder, E.R. 1965. The physics of ice. Oxford, Pergamon Press.

Robin, G. de Q. 1979. Formation, flow, and disintegration of ice shelves. J. Glaciol., 24(90), 259-271.

Röthlisberger, H. 1983. Snow and slush on floating lake ice. Ann. Glaciol., 4, 236-240.

Rusin, N.P. 1964. Meteorological and radiational regime of Antarctica. Jerusalem, Israel Program for Scientific Translations.

Schwerdtfeger, P. 1963. The thermal properties of sea ice. J. Glaciol., 4(36), 789-807.

Semtner, A.J., jr. 1976. A model for the thermodynamic growth of sea ice in numerical investigations of climate. J. Phys. Oceanogr., 6(3), 379-389.

Stefan, J. 1889. Uber die Theorie der Eisbildung, insbesondere über die Eisbildung im Polarmeere. Sitzungsber. Math-Naturwiss. Kl. Kaiserlichen Akad. Wiss. (Wien), 98(2a), 965-983.

Thompson, D.C. and W.J.P. MacDonald. 1962. Radiation measurements at Scott Base. N.Z. J. Geol. Geophys., 5, 874-909.

Tressler, W.L. and A.M. Ommundsen. 1962. Seasonal oceanographic studies in McMurdo Sound, Antarctica. Washington, DC, U.S. Navy Hydrographic Office. (Tech. Rep. TR-125.)

Untersteiner, N. 1961. On the mass and heat budget of Arctic sea ice. Arch. Meteorol. Geophys. Bioclimatol., Ser. $A, 12(2), 151-182$.

Wadhams, P., M.A. Lange, and S.F. Ackley. 1987. Ice thickness distribution across the Atlantic sector of the Antarctic Ocean in midwinter. J. Geophys. Res., 92(C13), $14535-14552$.

Wright, C.S. and R.E. Priestley. 1922. British (Terra Nova) Antarctic Expedition 1910-1913. Glaciology. London, Harrison and Sons.

Zaitseva, N.A. and V.I. Shlyakhov. 1984. Results of multi-year research on long-wave radiation in the Antarctic atmosphere. Antarct. Comm. Rep., 17, 90-98. 